\title{
CONSIDERAÇÕES SOBRE AS AVALIAÇÕES EM LARGA ESCALA NO BRASIL E O PAPEL DOS ORGANISMOS INTERNACIONAIS: EFICIÊNCIA E PRODUTIVIDADE X QUALIDADE ${ }^{1}$
}

\author{
Quelli Cristina da Silva Oliveira ${ }^{2}$ \\ Denila Coelho ${ }^{3}$ \\ André Paulo Castanha ${ }^{4}$
}

\begin{abstract}
Resumo: Esse texto realiza uma análise acerca das condições históricas, políticas e ideológicas sobre as avaliações externas em larga escala, e as interferências dos organismos internacionais nesse setor. Para tanto, realizamos estudo bibliográfico e documental. A partir deles percebemos forte influência das políticas do Banco Mundial e de organismos internacionais nas avaliações em larga escala no Brasil. Destacamos a relevância das avaliações, como mecanismo que possibilitam levantar elementos para elaboração de políticas públicas no campo educacional. Evidenciamos a necessidade de um sistema de avaliação que trate da educação na totalidade e proporcione uma efetiva melhoria da qualidade do ensino.
\end{abstract}

Palavras-Chave: Avaliação Externa. Organismos Internacionais. Capital Humano. IDEB. PISA.

\begin{abstract}
This essay intend to do an analyze around the historic, politic and ideological conditions which are involved in the large scale external evaluations and the international organisms interference in the area. Due to, it was done a bibliographic and data study. From the reflections, it was possible to detect the influence of this international organism in the large scale evaluation in Brazil. It was possible to see the relevance of the evaluations when they are used as an instrument that contributes to the elaboration of public politics in the educational field. It is evident the need of an evaluation system which works with the education in the totality and provide an effective improvement in the education qualit.
\end{abstract}

Key Words: External Evaluation. International Organisms. Human Capital. IDEB. PISA.

\section{Introdução}

\footnotetext{
1 Uma versão preliminar do presente texto foi apresentada e publicada nos Anais da X ANPED SUL, realizada na UDESC - Florianópolis-SC, entre 26 e 29 de outubro de 2014. Disponível no seguinte endereço: http:/ / xanpedsul.faed.udesc.br/arq_pdf/1256-0.pdf

${ }^{2}$ Mestre em Educação pela Unioeste, campus de Francisco Beltrão. E-mail: quellipro@yahoo.com.br

${ }^{3}$ Mestre em Educação pela Unioeste, campus de Francisco Beltrão. E-mail: denilacoelho@hotmail.com

${ }^{4}$ Professor do Colegiado de Pedagogia e do Mestrado em Educação da Unioeste - Campus de Francisco Beltrão - PR. Membro do Grupo de Pesquisa: História, Sociedade e Educação no Brasil - HISTEDOPR GT local do HISTEDBR. Historiador e mestre em Educação pela UFMT, Doutor em Educação pela UFSCar e Pós-doutor na área de Filosofia e História da Educação pela UNICAMP. Bolsista Produtividade da Fundação Araucária - PR. E-mail: andrecastanha66@gmail.com
} 
Este artigo tem como objetivo analisar o papel dos organismos internacionais frente às avaliações externa em larga escala no Brasil. Para tanto, além do uso de bibliografias, também utilizamo-nos de documentos oficiais de organismos internacionais e do Instituto Nacional de Estudos e Pesquisas Educacionais Anísio Teixeira (INEP).

O Estado brasileiro vem intensificando a instauração do Sistema de Avaliação da Educação Básica - SAEB, a Prova Brasil, o Exame Nacional de Desempenho de Estudantes - ENADE, o Índice de Desenvolvimento da Educação Básica - IDEB e o Exame Nacional do Ensino Médio - ENEM, tendo como fundamentação a eficiência e a produtividade para atender as necessidades do mercado de trabalho. Nesse sentido, a educação é tratada como mercadoria, com o intuito de formar o trabalhador voltado para o fazer, submisso e com uma visão política limitada.

A grande questão que nos inquieta é, até que ponto essas avaliações do Estado na forma como estão constituídas contribuem para a melhoria do processo educativo? $\mathrm{O}$ debate que se segue é uma tentativa de compreender melhor essa indagação. $\mathrm{O}$ texto está organizado da seguinte forma: iniciamos tratando da avaliação em larga escala e as relações entre o PISA e o IDEB, os aspectos históricos e a política da Terceira Via, e por fim, abordamos a teoria do capital humano, o SAEB e suas avaliações.

\section{Avaliação em larga escala e as interferências internacionais: relações entre PISA e IDEB.}

A discussão dos problemas da educação básica no Brasil e os desafios objetivando a melhoria da qualidade têm sido marcados nos últimos anos pela divulgação mais ampla de informações produzidas pelo sistema de avaliação externa em larga escala, focada no rendimento do aluno e no desempenho dos sistemas de ensino, a partir de um índice - IDEB. Para entendermos esse contexto iremos discorrer sobre as parcerias e estratégias dos organismos internacionais, referentes à educação brasileira.

O Banco Mundial vem investindo atualmente em aperfeiçoamento dos sistemas de educação e no alinhamento das intervenções estaduais e federais nos estados. Apoiando melhorias no desempenho (qualidade) e na prestação de contas (indicadores), bem como no aumento da contribuição do ensino para a inovação e crescimento. 
Anterior a esta política a estratégia era a expansão da cobertura, ou seja, o acesso a educação (BANCO MUNDIAL E CFI, 2008, p. 22).

Os últimos anos vêm sendo marcados pelas mudanças na política dos organismos internacionais. Um dos documentos que descreve quais são estas mudanças, é o Banco Internacional para Reconstrução e Desenvolvimento - BIRD: Estratégias de Parcerias com o Brasil 2008-2011. Pelo documento observamos que o envolvimento do Banco demonstra interesse em elevar o Brasil nos seguintes campos: equidade (campo educacional), sustentabilidade (questões ambientais), competitivismo (educação para inovação e crescimento) e profissionalização, fomentando a regulamentação internacional.

Evidencia-se dessa forma que as políticas públicas do Brasil estão alinhadas aos interesses dos Organismos Internacionais que seguem a lógica do mercado. Assim, não podemos deixar de considerar o financiamento dessas ações, pois os investimentos, de forma alguma, caracterizam doação. O retorno para sanar a dívida, depende do desenvolvimento do capital humano, sendo a educação considerada essencial nesse processo.

A educação, como um fenômeno que se internacionaliza, compreende a expansão da escolarização de massas para patamares mais altos de ensino, a difusão da ideologia da modernização e do desenvolvimento econômico, as relações de cooperação e intercâmbio científicos entre os sistemas nacionais de ensino, a educação comparada e, sobretudo, a mediação das organizações supranacionais - UNESCO, Organização para a Cooperação e Desenvolvimento Econômico (OCDE), Banco Mundial, Banco Interamericano de Desenvolvimento, FMI, OMC, OIT, Usaid, Fundação Europeia da Cultura, Fundação Ford, Fundação Rockfeller e Fundação Carnegie, bem como entidades de caráter regional, a exemplo da Cepal, Orealc, Mercosul, no âmbito da América Latina, e União Europeia, União das Indústrias da Comunidade Europeia (Unice), MesaRedonda dos Industriais Europeus (European Round Table) -, com o que os diferentes Estados-nações têm redefinido, dentro do atual estágio de acumulação capitalista, o papel da escola e da universidade (SILVEIRA, 2012, p. 02).

Financiamento este que exige um plano estratégico de resultados, os quais abrangem as seguintes questões: objetivos de desenvolvimento do país, metas do 
governo e resultados das Estratégias de Assistência ao País - EAP. A estratégia do Banco Mundial na parceria com o Brasil busca:

[...] uma ênfase mais acentuada na contribuição do desenvolvimento humano para a "agenda de equidade" $\mathrm{e}$ ampliará esse enfoque de modo concorrente para que se reconheça a importância do capital humano e das inovações na "agenda do crescimento". Apesar dos avanços históricos nos indicadores sociais, persistem os desafios para a "agenda de equidade", tanto em termos de expansão da oferta de empregos e das oportunidades de renda para os pobres, fortalecendo seu capital humano, quanto a oferta de serviços com preços acessíveis, qualidade e eficiência. As grandes disparidades regionais também são encontradas nas taxas de pobrezas, de aproveitamento escolar e de mortandade infantil. Desta mesma forma o fortalecimento do capital humano é essencial para a agenda de crescimento, em termos de desenvolvimento de uma força de trabalho mais qualificada, saudável e ágil, capaz de inovar e se adaptar às novas tecnologias para aumentar a produtividade total dos fatores (BANCO MUNDIAL E CFI, 2008, p. 53).

O papel dos organismos internacionais, nas ideologias disseminadas pelos Estados, de acordo com Silveira (2012, p. 03 - 04) “[...] tem sido essencial na elaboração e difusão da ideologia desenvolvimentista e educativa em nível mundial, normatizando, controlando e legitimando a produção do conhecimento considerado vital para a conservação do capitalismo".

É possível perceber um leque dentro do campo de atuação e os objetivos dos Organismos Internacionais, buscando auxiliarem os Estados de forma combinada com um crescimento desigual, mantendo a hegemonia do capital. No entendimento de Silveira,

Reconhecendo as desigualdades econômico-sociais, educacionais, tecnocientíficas dos diferentes Estados-nações e delas partindo, os organismos supranacionais buscam combinálas e integrá-las em suas particularidades e contradições, impulsionando o desenvolvimento desigual e combinado da sociedade capitalista, cuja tática se desvela no movimento e realização internos do telos $^{5}$ da estratégia (2012, p.04).

\footnotetext{
${ }^{5}$ Palavra grega com significado: finalidade, fim, meta, objetivo (Dicionário Informal).
} 
O crescimento econômico mundial depende de investimentos em três áreas: a saúde (menor mortandade infantil), educação e questões ambientais. Sem investimentos nestes setores o crescimento econômico fica estagnado, por isso os esforços em melhorias e "equidade".

Nesse sentido, Dale (2004, p. 454) nos chama atenção para uma "cultura educacional mundial comum" CEMC, a essência dessa perspectiva de educação busca o desenvolvimento dos sistemas educativos dos Estados e de um currículo com elemento universal de educação, de estado e de sociedade, mais do que através de fatores nacionais. Levando em consideração os investimentos do Banco Mundial e o fato de seu maior acionista ser os Estados Unidos, fica demonstrada a dominância nos princípios de formulação das políticas públicas mundiais e a fundamentação da CEMC.

Criam-se assim, uma "falsa democracia" que se instaurou no Brasil, fortemente, a partir da década de 1980 com apoio dos organismos internacionais (países em crise econômica, Europa e Estados Unidos). Houve mudanças significativas, com a falência de um Estado de Bem-Estar, abrindo espaço para o Estado neoliberal. O que antes era tarefa do governo, passou a ser agora sinônimo de cidadania. Thais Souza em seu texto (Con) Formando Professores Eficazes enfatizou que:

Foi nesse contexto que a educação, mais uma vez torna-se peçachave para a formação de um determinado tipo de cidadão, $o$ qual deveria ser moldado para aceitar a exploração e colaborar cordialmente com a manutenção da ordem do capital sobre o trabalho, pois forma sujeitos difusores da concepção burguesa de mundo. Diante da crise hegemônica de ambos os modelos, no Brasil, da década de 1980 até os dias atuais, outra forma de governo democrático emergiu: o Projeto da Terceira Via (SOUZA, 2009, p. 36, grifo do autor).

Em meio uma crise econômica mundial e o Brasil passando por um período de estagnação pelo comando militar (1964 - 1985), os anseios pela democracia se instaura fortemente na sociedade. A ideia de mudanças governamentais foi incorporada com um discurso apontando para um modelo de governo pautado na política de Terceira via ${ }^{6}$.

\footnotetext{
${ }^{6}$ Ela se refere à renovação da democracia social (GIDDENS, 2007, p. 21).
} 
O projeto de terceira via, trouxe possibilidade de implementar uma política governamental, perspectivas de superação de governos ditatoriais e os neoliberais. No entanto, se analisarmos o contexto histórico posterior a Ditadura militar no Brasil, após um período de muita recessão, houve uma significativa estruturação do sistema escolar voltado para o tecnicismo oriundo da Ditadura e das organizações, como por exemplo os sindicatos, que representavam os profissionais de todos os níveis de ensino (GIDDENS, 2007, p. 21).

No período de 1990 e 2001, as mudanças de cunho neoliberalista e as ações voltadas para produção de resultados, possibilitem compreender melhor a "falsa democracia”, e porque o projeto de Terceira via não se concretizou. Mudou-se da ditadura militar, para a "democracia" do mercado, da produtividade e dos resultados. Conforme Saviani,

Redefine-se, portanto, o papel tanto do Estado como das escolas. Em lugar da uniformização e do rígido controle do progresso, como preconizava o velho tecnicismo inspirado no Taylorismofordismo, flexibiliza-se o progresso, como recomenda o toyotismo. Estamos, pois, diante do neotecnicismo: o controle decisivo desloca-se do progresso para o resultado. É pela avaliação dos resultados que se busca garantir a eficiência e a produtividade. E a avaliação converte-se no papel principal a ser exercido pelo Estado, seja mediatamente, pela criação das agências reguladoras, seja diretamente, como vem ocorrendo no caso da educação. Eis porque a nova LDB (Lei nº 9394 de 20 de dezembro de 1996) enfeixou no âmbito da União a responsabilidade de avaliar o ensino em todos os níveis, compondo um verdadeiro sistema nacional de avaliação. E para desincumbir-se dessa tarefa o governo federal vem instituindo exames e provas de todos os tipos. Trata-se de avaliar os alunos, as escolas, os professores e, a partir dos resultados obtidos, condicionar a distribuição de verbas e alocação de recursos conforme os critérios da eficiência e da produtividade (2010, p. 439).

Toda essa mudança no contexto educacional brasileiro foi provocada pelos organismos internacionais, a eficiência e a produtividade provêm de uma lógica de desenvolvimento econômico. A Organização para Cooperação e Desenvolvimento Econômico - OCDE é um dos organismos que instituiu programas de avaliações externas em países integrantes e colaboradores como o Brasil, a intencionalidade 
principal foi criar leis, documentos e principalmente mecanismos de controle que comprovem avanços em relação à lógica do desenvolvimento.

O sistema educacional é um dos focos principais de reformulação e controle a partir de avaliações em larga escala. Um exemplo disso é o Programa Internacional de Avaliação de Alunos - PISA. O PISA é apresentado no portal do INEP desta forma:

O Programme for International Student Assessment (PISA) Programa Internacional de Avaliação de Estudantes - é uma iniciativa internacional de avaliação comparada, aplicada a estudantes na faixa dos 15 anos, idade em que se pressupõe o término da escolaridade básica obrigatória na maioria dos países.

O programa é desenvolvido e coordenado pela Organização para Cooperação e Desenvolvimento Econômico (OCDE). Em cada país participante há uma coordenação nacional. No Brasil, o Pisa é coordenado pelo Instituto Nacional de Estudos e Pesquisas Educacionais Anísio Teixeira (INEP).

O objetivo do Pisa é produzir indicadores que contribuam para a discussão da qualidade da educação nos países participantes, de modo a subsidiar políticas de melhoria do ensino básico. A avaliação procura verificar até que ponto as escolas de cada país participante estão preparando seus jovens para exercer o papel de cidadãos na sociedade contemporânea. As avaliações do Pisa acontecem a cada três anos e abrangem três áreas do conhecimento - Leitura, Matemática e Ciências - havendo, a cada edição do programa, maior ênfase em cada uma dessas áreas. Em 2000, o foco foi em Leitura; em 2003, Matemática; e em 2006, Ciências. O Pisa 2009 iniciou um novo ciclo do programa, com o foco novamente recaindo sobre o domínio de Leitura; em 2012, é novamente Matemática; e em 2015, Ciências. Além de observar as competências dos estudantes em Leitura, Matemática e Ciências, o Pisa coleta informações para a elaboração de indicadores contextuais, os quais possibilitam relacionar o desempenho dos alunos a variáveis demográficas, socioeconômicas e educacionais. Essas informações são coletadas por meio da aplicação de questionários específicos para os alunos e para as escolas.

Os resultados desse estudo podem ser utilizados pelos governos dos países envolvidos como instrumento de trabalho na definição e refinamento de políticas educativas, procurando tornar mais efetiva a formação dos jovens para a vida futura e para a participação ativa na sociedade (BRASIL, PISA, 2014).

A partir dos resultados do PISA e sendo ele, no Brasil, coordenado pelo INEP, torna-se evidente que houve atenção maior para melhorar tais resultados. O PISA 
impulsionou as discussões e possibilitou a ampliação de políticas referente as avaliações em larga escala no país. Segundo Machado

A comparação de rendimento entre países atrai a atenção dos meios de comunicação e do público em geral. Desde a primeira edição do pisa os resultados do teste são amplamente divulgados nos países participantes. Pode-se considerar esse um aspecto positivo, uma vez que, ao tomar conhecimento dos resultados, pode haver um desejo de atuar para melhorá-los, em especial quando são decepcionantes (2012, p. 38).

Nesse sentido, o Observatório Regional Base de Indicadores de Sustentabilidade ORBIS, destaca que:

Para melhorar esta situação, foi criado pelo Instituto Nacional de Estudos e Pesquisas Anísio Teixeira, o INEP, em 2007, o Índice de Desenvolvimento da Educação Básica - IDEB, um importante passo para avaliar a qualidade de ensino no país. Principalmente pela possibilidade de comparação entre municípios e escolas de diferentes dependências administrativas (públicas - municipais, estaduais e federais - e particulares).

O IDEB sintetiza dois conceitos igualmente importantes para a qualidade da educação: aprovação (progressão) e o desempenho dos estudantes em língua portuguesa e matemática, gerando um índice numa escala de zero a dez. A meta deste índice para o Brasil é alcançar a nota 6,0 até 2022.

As metas do IDEB foram definidas com base no nível médio atual de qualidade educacional dos países desenvolvidos, membros da Organização para Cooperação do Desenvolvimento Econômico (OCDE). O ano de 2022 foi escolhido em alusão ao bicentenário da Independência do Brasil (1822 - 2022), simbolizando a liberdade que a educação representa $(2010, \mathrm{~s} / \mathrm{p})$.

Segundo o ORBIS, houve uma pequena melhora do Brasil nos indicadores do PISA. Nesta análise, registra-se uma redução na diferença de 19\% no desempenho de matemática, $17 \%$ em leitura e $14 \%$ em ciências, do país em relação aos países membros da OCDE, comparando os resultados de 2006 com os de 2000, necessitando assim de esforço para se aproximar dos níveis de qualidade apresentados como ideais nessa avaliação (2010, s/p).

Na comparação de dados entre 2003 e 2012, referentes ao PISA, conforme o Relatório Nacional PISA 2012 (p. 63), o Brasil apresenta evolução nos resultados, maior inclusão dos estratos menos favorecidos da sociedade, redução na distorção idade-série e nas desigualdades regionais. $\mathrm{O}$ documento ressaltou que estamos longe de 
nos aproximarmos dos países com melhor desempenho e aponta problemas com a infraestrutura das escolas, equipamentos educacionais, número de professores, altos índices de repetência, dentre outros.

Os conhecimentos exigidos tanto no PISA, quanto nas avaliações em larga escala que compreendem o Sistema de Avaliação da Educação Básica - SAEB, exigem conhecimentos mínimos de leitura, interpretação e lógica, o que pode justificar essa pequena melhora no indicativo do PISA.

O Ideb (Índice de Desenvolvimento da Educação Básica) é o indicador objetivo para a verificação do cumprimento das metas fixadas no Termo de Adesão ao Compromisso "Todos pela Educação", eixo do Plano de Desenvolvimento da Educação, do Ministério da Educação, que trata da educação básica. É nesse âmbito que se enquadra a ideia das metas intermediárias para $\mathrm{o}$ Ideb. A lógica é a de que, para que o Brasil chegue à média 6,0 em 2021, período estipulado tendo como base a simbologia do bicentenário da Independência em 2022, cada sistema deve evoluir segundo pontos de partida distintos, e com esforço maior daqueles que partem em pior situação, com um objetivo implícito de redução da desigualdade educacional.

A definição de uma meta nacional para o Ideb em 6,0 significa dizer que o país deve atingir em 2021, considerando os anos iniciais do ensino fundamental, o nível de qualidade educacional, em termos de proficiência e rendimento (taxa de aprovação), da média dos países desenvolvidos (média dos países membros da OCDE) observada atualmente. Essa comparação internacional foi possível devido a uma técnica de compatibilização entre a distribuição das proficiências observadas no PISA e no Saeb (INEP, 2014).

É possível perceber alguns avanços, quando reconhecemos que a educação precisa de parâmetros que a qualifiquem. Faz-se necessário avaliar nossa prática de ensino e aprendizagem e sua finalidade, bem como as políticas públicas de educação e a práxis que se instaura no interior da escola.

Para melhor contextualizar as avaliações em larga escala e como estas foram ganhando espaço nas formulações das políticas educacional brasileiras no próximo tópico analisaremos o Sistema de Avaliação da Educação Brasileira - SAEB.

\section{O Sistema de Avaliação da Educação Brasileira: SAEB}


As políticas para a educação básica no Brasil e o Sistema de Avaliação da Educação Básica -SAEB, percorreram caminho para chegar a "inclusão" dos alunos no sistema escolar com a finalidade de melhorar as estatísticas perante os organismos internacionais e garantir a formação com princípios da eficiência e produtividade. Embora tenha sido escrita em outro período histórico entendemos como relevante e pertinente às considerações de Shiroma, Moares e Evangelista

[...] os reformadores disseminam um discurso fundamentado em pressupostos questionáveis. Afirmam que a educação constituise numa das principais vias de enfrentamento dos problemas atuais, especialmente o da inserção ou manutenção do indivíduo no mercado de trabalho. Valorizam os atributos e conhecimentos próprios do ensino formal, como se a eficiência do ensino formal fosse, por si só, capaz de promover a eficiência da economia. Mais que isso, tentam creditar a morosidade da economia à suposta obsolescências do conhecimento dos trabalhadores, argumento equívoco e derrubado por inúmeras pesquisa. Trata-se, então, de destacar sua função ideológica, cujo o intento é responsabilizar a população pela situação do país na economia globalizada lastreada na voluntarista ideia de que o país superará sua posição periférica na divisão internacional do trabalho se cada cidadão investir adequadamente em sua própria escolarização e requalificação (2007, p. 93).

Quando os "reformadores" falam de reformas educacionais, se remetem a uma perspectiva de conceber a educação como elemento crucial para equalização do desenvolvimento, portanto do aquecimento da economia, apontando para os indivíduos a culpa pelos problemas estruturais e a responsabilidade de aumentar seu capital humano.

Os próprios reformistas indicam que a eficiência do ensino objetiva a busca por elevar conhecimentos e manter o mercado. O qual está cada vez mais exigente e concorrido, fazendo com que os próprios educadores e, consequentemente os alunos internalizem e naturalizem que o conhecimento ensinado na escola atual está elevando os padrões de qualidade e equidade estabelecidos pelo Estado.

Nesta perspectiva a educação é concebida como capital humano, sendo um dos principais instrumentos de massificação em prol do desenvolvimento do mercado e fomento do grande capital. 
Sobre a teoria do capital humano Frigotto (2010, p. 51) aponta que "a educação, então, é o principal capital humano enquanto é concebida como produtora de capacidade de trabalho, potencializadora do fator trabalho. Neste sentido, é um investimento como qualquer outro". O processo educativo, independentemente de ser escolar, se reduz a produzir habilidades e transmitir conhecimentos que aumentem a capacidade de trabalho e de produção.

A análise econômica da educação, veiculada pela teoria do capital humano, funda-se no método e pressupostos de interpretação da realidade da economia neoclássica. Este modo de interpretação da realidade é um produto histórico determinado que nasce com a sociedade de classes e se desenvolve dentro e na defesa dos interesses do capital (FRIGOTTO, 2010, p. $65-66$ ).

A teoria do capital humano apresentada nos anos de 1970 procurava explicar as desigualdades tanto entre as nações quanto as individuais, através do fraco investimento em educação. Fator este considerado determinante da capacidade de trabalho e produtividade (FRIGOTTO, 2010, p. 15). Seguindo a lógica dessa teoria, para garantir o crescimento e o desenvolvimento da sociedade é preciso investir na educação, o que significaria grandes possibilidades de ascensão econômica.

O direcionamento do Banco Mundial e da OCDE, continuaram determinando diretamente as propostas e ações, as quais fortaleceram a reforma educacional, dentre elas citamos a criação do SAEB.

O Sistema Nacional de Avaliação da Educação Básica (Saeb), foi criado em 1990 e, desde 1995, realiza seu ciclo de avaliação a cada dois anos. O Saeb foi criado tendo por objetivo central promover uma avaliação externa e em larga escala da educação no Brasil, visando construir dois tipos de medidas. A primeira, da aprendizagem dos estudantes e, a segunda, dos fatores de contexto correlacionados com o desempenho escolar. A implementação da avaliação em larga escala se constituiu com a intenção de subsidiar os formuladores e executores das ações governamentais na área educacional em todos os níveis de governo. Com a avaliação se pretende averiguar a eficiência dos sistemas no processo de ensino-aprendizagem e, também, a equidade da educação oferecida em todo o país (BRASIL, MEC, 2010). 
O SAEB iniciou com a Avaliação Nacional da Educação Básica - ANEB e com a Avaliação Nacional do Rendimento Escolar - ANRESC, para qual, iremos direcionar nossa análise.

Conforme indicado no Plano Nacional de Desenvolvimento da Educação, BRASIL (2008, p.8). “A avaliação denominada ANRESC (Prova Brasil), é realizada a cada dois anos", avalia as habilidades em Língua Portuguesa (foco na leitura) e em matemática (foco na resolução de problema)". Se apresenta como uma avaliação censitária envolvendo os alunos da $4^{\mathrm{a}}$ série/ $5^{\circ}$ ano e $8^{\mathrm{a}}$ série/ $9^{\circ}$ ano do Ensino Fundamental das escolas públicas das redes municipais, estaduais e federal, em turmas com mais de 20 alunos e com o objetivo de avaliar a qualidade do ensino ministrado nas escolas públicas. Tem como método de avaliação a Prova Brasil de Língua Portuguesa e Matemática.

Os critérios estabelecidos foram baseados em modelos educacionais que pouco tem haver com a realidade brasileira e, principalmente, avaliando o que o mercado define como prioridade para identificar competências e habilidades, como é o caso da ênfase no ensino de Português (Língua Portuguesa) e o ensino lógico (Matemática), em detrimento das outras áreas do conhecimento.

Essas perspectivas fortaleceram a ideia de que o sucesso ou insucesso depende do aluno e do professor, responsabilizando a qualidade do trabalho ao educador, o qual deve ter um perfil de iniciativa e dedicação para atingir as metas. Ficando isso bem evidente no Plano Nacional de Educação, na transição do Governo do presidente Fernando Henrique Cardoso, para Luiz Inácio Lula da Silva, delineando as reformas educacionais.

Havia uma expectativa de mudança na política educacional por conta da troca de governo, com a possibilidade de alterações no PNE, Lula participou diretamente na construção do PNE pela sociedade e seu encaminhamento à câmara dos deputados, que acabou não se efetivando. Segundo Saviani (2010, p. 450-451):

[...] o texto original elaborado pela sociedade, foi drasticamente alterado pelo governo anterior, não permitindo muitos avanços na qualidade da educação e o atual governo não alterou os vetos apresentados. Deixando explícito logo no início de 2003, que não seriam alteradas as linhas básicas de ação governamental, nas políticas econômicas e sociais. 
Conforme demostrado por, Tommasi, Warde e Haddad, (2010, p. 450-451):

O ensino de primeiro grau é a base e sua finalidade fundamental é dupla: produzir uma população alfabetizada e que possua conhecimentos de aritmética capaz de resolver problemas no lar e no trabalho e servir de base para posterior educação.

Em 24 de abril 2007, o MEC, lançou o Plano de Desenvolvimento da Educação com o intuito de elevar a qualidade do ensino brasileiro, simultaneamente com o Decreto 6.094, criando o Plano de Metas Compromisso Todos pela Educação. Contando com o engajamento da União, dos Estados, o Distrito Federal e dos Municípios, em regime de colaboração, para superar a condição atual da educação brasileira, de desigualdade nas oportunidades perante a globalização (SAVIANI, 2009).

Mais uma vez as reformas objetivam a diminuição das desigualdades perante a globalização. Concepção que está pautada no individualismo, competitividade, dualidade do ensino para atender um mercado em crise. Portanto, as avaliações externas em larga escala no contexto educacional brasileiro estão fundamentadas nas políticas de organismos internacionais como a OCDE, que desenvolveu o PISA, o qual vem servindo de modelo, com algumas alterações, como maior abrangência das modalidades de ensino.

No Brasil, em 2013 foi expedida a Portaria 482/ 2013 que trata do SAEB e sua composição. O SAEB passou a ser integrado pelos seguintes processos de avaliações: Avaliação Nacional da Educação Básica (ANEB), Avaliação Nacional do Rendimento Escolar (ANRESC) e a Avaliação Nacional da Alfabetização (ANA). Segundo a proposta do INEP (2013, p.9):

A Avaliação Nacional da Alfabetização (ANA) produzirá indicadores que contribuam para o processo de alfabetização nas escolas públicas brasileiras. Para tanto, assume-se uma avaliação para além da aplicação do teste de desempenho ao estudante, propondo-se, também, uma análise das condições de escolaridade que esse aluno teve, ou não, para desenvolver esses saberes.

A estrutura dessa avaliação envolve o uso de instrumentos variados, cujos objetivos são: aferir o nível de alfabetização e letramento em Língua Portuguesa e alfabetização em Matemática das crianças regularmente matriculadas no $3^{\circ}$ ano do 
ensino fundamental e as condições das instituições de ensino às quais estão vinculadas.

$\mathrm{O}$ artigo $7^{\circ}$ da portaria 482, definiu claramente o poder do Inep, na definição das características e objetivos da avaliação em larga escala no Brasil. Conforme documento:

O planejamento e a operacionalização da ANEB, ANRESC e ANA são de competência do Instituto Nacional de Estudos e Pesquisas Anísio Teixeira - INEP, por meio da Diretoria de Avaliação da Educação Básica - DAEB, que deverá:

I - definir os objetivos específicos de cada pesquisa a ser realizada, alinhados às diretrizes definidas pelo Ministério da Educação - MEC e pelo Conselho Nacional de Educação - CNE, os instrumentos a serem utilizados, as séries e disciplinas, bem como as competências e as habilidades a serem avaliadas;

II - definir abrangência, mecanismos e procedimentos de execução da pesquisa;

III - implementar a pesquisa em campo; e

IV - definir as estratégias para disseminação dos resultados. PARÁGRAFO ÚNICO - O planejamento de cada uma das pesquisas definirá parâmetros básicos inerentes às aplicações anuais, que serão estabelecidos em Portaria específica do INEP. (BRASIL, 2013, p.13).

A portaria não deixa claro se os resultados da Avaliação Nacional da Alfabetização entraram na base de cálculo do IDEB, índice que vem sendo utilizado como o principal parâmetro de qualidade para a educação brasileira. O INEP é o responsável pela definição dos critérios para esse parâmetro que estão baseados nas notas de 0 a 10, sendo calculado com base no desempenho do estudante na Prova Brasil (Língua Portuguesa e Matemática) e as taxas de aprovação, reprovação e evasão (fluxo).

Parece-nos que a ideia de avaliação externa em larga escala no Brasil está consagrada no SAEB. Entendemos que, é um direito do cidadão conhecer se a realidade e qualidade da educação brasileira e um dever do Estado, para utilizar-se dessas informações e ampliar as políticas educacionais. Infelizmente, as avaliações realizadas até o momento, têm servido mais para elevar as estatísticas, do que para garantir a efetiva qualidade na educação.

\section{Considerações finais}


Este estudo sobre o papel dos organismos internacionais frente às avaliações externa em larga escala no Brasil demonstra como as políticas do Banco Mundial e outros organismos fundamentaram as reformulações ocorridas na educação. Primeiramente com a inserção do país como colaborador na OCDE no PISA e, posteriormente com a criação do SAEB.

Analisando os objetivos de qualidade e equidade na educação brasileira percebese uma relação com a política de desenvolvimento econômico que prioriza algumas áreas do conhecimento em detrimento das outras, que também são fundamentais para a formação do indivíduo. Isso chama a atenção para a necessidade de verificarmos como os outros determinantes que envolvem o espaço escolar, tais como: realidade social, formação de professores e estrutura da escola estão sendo considerados pelo Estado nessas avaliações. Os idealizadores imaginam que cada meta do Plano Nacional de Educação evolua de forma a contribuir, em conjunto, para que o Brasil atinja o patamar educacional da média dos países da OCDE, mas esquecem-se de que tais países apresentam contextos muito diferentes do Brasil.

O problema não está em avaliar o sistema nacional de educação. O que se questiona é a estruturação da avaliação, os fundamentos e os objetivos que estão pautando as avaliações, bem como os encaminhamentos tomados a partir dos resultados obtidos.

A avaliação como está constituída não avalia o sistema educacional com objetivo de melhorar a qualidade da educação, formação do trabalhador e sua força de trabalho. Além disso, explicitamente leva há um processo de culpabilização dos educandos e dos educadores em relação ao resultado dos índices que representam "qualidade".

A política neoliberal baseada no estado mínimo e com ênfase nos resultados, individualiza o educando, cobra a eficiência e tem na avaliação em larga escala uma forma de controle. Em contraposição, a avaliação enquanto processo formativo traz consigo a consciência política do ato de educar e baseia-se na análise dos resultados obtidos, considerando todos os elementos de um ensino de qualidade. Para tanto, o Estado deve se responsabilizar efetivamente por uma política educacional que atenda a realidade do Brasil, objetivando concretamente a qualidade e a equidade em sua totalidade. 
Temos ciência de que a educação formal por si só não é capaz de transformar a realidade social em que vivemos, no entanto, acreditamos que uma educação de qualidade pode auxiliar e proporcionar novas formas de organização social. Conforme Mészáros (2008, p. 45):

Uma das funções principais da educação formal nas nossas sociedades é produzir tanto a conformidade ou "consenso" quanto for capaz, a partir de dentro e por meio dos seus próprios limites institucionalizados e elegantemente sancionados. Esperar da sociedade mercantilizada uma sanção ativa - ou mesmo mera tolerância - de um mandato que estimule as instituições de educação formal a abraçar plenamente a grande tarefa histórica de nosso tempo, ou seja, a tarefa de romper com a lógica do capital no interesse da sobrevivência humana, seria um milagre monumental. É por isso que, também no âmbito educacional, as soluções "não podem ser formais; elas devem ser essenciais". Em outras palavras, eles devem abarcar a totalidade das práticas educacionais da sociedade estabelecida.

Afinal, as mudanças serão vistas como possibilidade quando conhecermos, entendermos e desprendermos das formalidades e das condições estabelecidas pelo capital. Ou seja, precisamos conhecer os fundamentos da política de avaliação e não se deixar levar facilmente pelos discursos ideológicos de inovações e avanços na educação. Por falta de conhecimentos, muitas vezes, os educadores acabam alimentando o sistema, desencadeando uma competitividade entre escolas, que contribui para desqualificar ainda mais os mecanismos de avaliação em larga escala. A práxis educativa deve ser construída para além da ideologia mercantilizada das avaliações em larga escala e seus índices, seu foco deve ser a efetiva qualidade na formação omnilateral dos alunos.

Assim, consideramos que os caminhos para uma educação de qualidade podem ser construídos também por vias não formais a partir da internalização do conhecimento na sua essência e, de uma consciência coletiva por parte dos educadores.

\section{Referências}

BANCO MUNDIAL e CFI. Estratégia de Parceria com o Brasil 2008 - 2011. Relatório $n^{o} 42677$ - BR. Brasília, DF: Banco Mundial. Departamento do Brasil. Região da América Latina e Caribe; Corporação Financeira Internacional, Departamento da América Latina e Caribe, 2008. 
MEC. PDE: Plano de Desenvolvimento da Educação: SAEB: ensino médio: matrizes de referência, tópicos e descritores. Brasília: MEC, SEB: Inep, 2008.

MEC: Sistema Nacional da Educação Básica. 2010 - Aneb e Anresc (Saeb). Disponível em: <http://gestao2010.mec.gov.br/o_que_foi_feito/program_77.php>. Acesso em: 11 jul 2013.

MEC/INEP. Relatório Nacional Pisa 2012: Resultados Brasileiros. Disponível em: <http://download.inep.gov.br/acoes_internacionais/pisa/resultados /2014/relatorio_nacional_PISA_2012_resultados_brasileiros.pdf >. Acesso em: 13 abr 2014.

MEC/INEP. Portaria $n^{\circ} 482$, de 07 de junho de 2013. Disponível em: <http://download.inep.gov.br/educacao_basica/prova_brasil>. Acesso em: 11 abr 2014.

MEC/INEP. Avaliação nacional da alfabetização (ANA): documento básico.

Brasília: INEP 2013. Disponível em:
<http://download.inep.gov.br/educacao_basica/saeb/2013/livreto_ANA_online.pdf.> Acesso em: 28 de abr. de 2014.

MEC/INEP. PISA $\quad$ Ideb. Disponível em: <http://portal.inep.gov.br/internacional-novo-pisa-opisaeideb>. Acesso em: 11 abr 2014.

MEC/INEP. PISA. Disponível em: <http://portal.inep.gov.br/pisa-programainternacional-de-avaliacao-de-alunos>. Acesso em: 11 abr 2014.

DALE, Roger. Globalização e Educação: demonstrando a existência de uma "cultura Educacional Mundial Comum" ou localizando uma "agenda globalmente estruturada para a educação"? Revista Educação \& Sociedade, v. 25, n. 87, maio/ago. 2004. ISSN: 0101-7330.

DICIONÁRIO INFORMAL. Disponível em: <http://www.dicionarioinformal.com.br/telos/>. Acesso em: 13 abr 2014.

FRIGOTTO, Gaudêncio. A Produtividade da Escola Improdutiva: um (re)exame das relações entre educação e estrutura econômico-social capitalista. 9. Ed. São Paulo: Cortez, 2010.

GIDDES. Anthony. O debate global sobre a terceira via. Tradução de Roger Maioli dos Santos. - São Paulo. 2007. Disponível em: <http://books.google.com.br/books?id=XjgPEWCe9IEC\&pg=PA276\&lpg=PA276\&dq $=$ anthony+giddens+terceira+via++livro+download \&source=bl\&ots=e2d3 Lyq70m\&sig= uh9FDbKsHkVYN0B34GBE_oG_oZo\&hl=ptBR\&sa=X\&ei=IBRLUHgM8S90AGQ_o GQDg\&ved $=0 \mathrm{CEwQ6AEwBQ} \# \mathrm{v}=$ twopage $\& \mathrm{q}=$ anthony $\% 20$ giddens $\% 20$ terceira $\% 20 \mathrm{vi}$ a\%20\%20livro\%20download\&f=true>. Acesso em: 13 abr 2014.

MACHADO. Veruska Ribeiro. Compreensão Leitora no PISA e práticas escolares de leitura-Brasília: Liber Livro; Faculdade de Educação/Universidade de Brasilía, 2012. 
MÉSZÁROS, István. A Educação para Além do Capital. (Tradução ISA Tavares). 2.ed.-São Paulo: Boitempo, 2008.

ORBIS. Educação: Abismo entre a Universalização do Acesso e a Qualidade no Ensino. Disponível em: < http://www.orbis.org.br/analise/6/educacao-abismo-entre-auniversalizacao-e-qualidade-no-ensino>. Acesso em: 13 abr 2014.

SAVIANI, Dermeval. História das Ideias Pedagógicas no Brasil. 3 ed. Campinas, SP: Autores Associados, 2010.

Dermeval. PDE: Plano de Desenvolvimento da Educação: Análise Crítica da Política do MEC. Campinas, SP: Autores Associados, 2009.

SHIROMA, Eneida Oto. MORAES, Maria Célia Marcondes. EVANGELISTA, Olinda. Políticas Educacionais. 4 ed. Rio de Janeiro: Lamparina, 2007.

SILVEIRA. Zuleide S. Organismos Supranacionais: a construção de uma concepção de mundo em torno da integração da educação superior - o caso do Brasil. Revista Trabalho Necessário, n. 14, 2012. ISSN: 1808 - 799X. Disponível em: <http://www.uff.br/trabalhonecessario/images/TN14Zuleide\%20S.pdf>. Acesso em 11 abr 2014.

SOUZA, Thaís Rabelo de. (CON)FORMANDO PROFESSORES EFICAZES: a relação política entre o Brasil e a Organização para Cooperação e Desenvolvimento Econômico $(O C D E)$. Dissertação de Mestrado - Universidade Federal Fluminense, Faculdade de Educação. 2009.

TOMASI, Livia de. Warde, Miriam Jorge. Haddad, Sérgio. O Banco Mundial e as Políticas Educacionais. 3 ed. São Paulo: Cortez, 2000. 